\title{
Gender-based Differences in Complimenting Behaviour: A Critical Literature Review
}

\author{
Nan Sun
}

\section{Abstract}

This paper provides a critical literature review of research that has examined gender differences in complimenting behaviour in English and Mandarin Chinese contexts. It first explores the functions of compliments in social life and describes the syntactic patterns and topics characterising the compliments of women and men, and then compares different types of complimenting responses used by English and Mandarin Chinese speakers. Finally, the paper discusses different interpretations of the findings offered by researchers, and identifies some research gaps for further in-depth analysis in this area.

\section{Introduction}

Compliments are common in various cultural and social contexts and are generally considered as a way to build or increase solidarity between the speaker and the addressee (Holmes, 1988). This paper analyses differences concerning compliments and compliment responses between women and men, based on previous studies conducted by researchers from two speech communities: English and Mandarin Chinese. The findings from these studies show that significant differences in complimenting behaviour across gender groups exist, including syntactic patterns and topic selections. Distributions of compliments also vary within the same gender group and across different gender groups. Women, in general, are found to give and receive compliments more often than men. Furthermore, women and men use different strategies to respond to compliments, and the gender of the interlocutor who pays the compliment is normally seen as an important factor in the English context. I consider two different explanations of the findings and suggest that, when comparing data from the two speech communities, cultural difference is a factor influencing women's and men's complimenting behaviour. 


\section{Compliment as a Speech Act and Its Functions}

Holmes's (1986b) definition of a compliment is widely used in literature:

A compliment is a speech act which explicitly or implicitly attributes credit to someone other than the speaker, usually the person addressed, for some 'good' (possession, characteristic, skill, etc.) which is positively valued by the speaker and the hearer.

As such, compliments can be described as 'social lubricants', which enable us to 'create or maintain rapport' (Wolfson, 1983). They are mostly used as politeness devices to express goodwill and build solidarity between the complimenter and the complimentee (Holmes, 1995), but in some contexts, as suggested by Herbert (1990), compliments serve as praise and encouragement. Herbert (1990) argues that instead of offering solidarity, compliments are likely to reflect the relationship between the complimenter and the complimentee, because praise is often directed towards the subordinate or less powerful participant.

In general, compliments are found to be multifunctional speech acts and the following summary from Holmes (1995) lists their functions as identified by different analysts:

1. to express solidarity

2. to express positive evaluation, admiration, appreciation or praise

3. to express envy or desire for hearer's possessions

4. as verbal harassment.

These functions may, however, overlap in certain contexts. Thus, it is necessary to take other factors (such as relationships between participants and social status) into consideration when analysing the differences in complimenting behaviour between women and men.

The theoretical frameworks that have been adopted in this paper are Brown and Levinson's politeness theory (1987) and Pomerantz's (1978) two general conditions that govern the act of responding to compliments. Politeness theory is relevant because of its focus on redressing face-threatening acts (known as FTAs). The theory describes politeness as showing concern for two face wants: (1) negative face, which is the need not to be imposed upon; and, (2) positive face, the need to be liked or admired (Brown and Levinson, 1987). Holmes's definition of a compliment supports the proposition that giving compliments appeals predominantly to people's positive face, as the complimenter wants the complimentee to feel good. Under some circumstances, however, compliments can be seen as FTAs because of their evaluative function. The notion of negative 
face is helpful in analysing compliment response behaviour as the complimentee is expected to choose his or her compliment response carefully, without appealing to the complimenter's negative face. Hence the politeness theory framework is useful in evaluating compliments as politeness strategies. In analysing different strategies of compliment responses, the following two conditions proposed by Pomerantz (1978) are used:

a. agree with the speaker

b. avoid self-praise.

With these two conditions, we can understand why certain compliment responses are used to avoid FTAs in conversation. Both frameworks are valid in analysing the data collected as well as interpreting gender-based differences that are revealed in complimenting behaviour.

\section{Syntactic Patterns, Topics and Distributions}

One may wonder: do women and men rely on the same syntactic patterns when paying compliments? The simple answer is no. In fact, studies have found that women use more 'personal focus' for the act of complimenting; i.e., women tend to be involved by using the pronoun ' $I$ ' in their compliments (Holmes, 1988; Herbert, 1990; Sun, 2002). In other words, the syntactic pattern I like NP (e.g. I like your haircut!) is more favoured by women than men. But in Holmes's (1988) New Zealand corpus, women are found to use the pattern What (a) (ADJ) NP! (e.g. What an interesting talk!) significantly more often than men. In contrast, men prefer the 'minimal pattern' (INT) ADJ (NP) (e.g. Nice outfit!) and use it more often than women. Similarly, in Duan and Guo's (2009) Mainland Chinese corpus, women are also found to have a more personal focus than men when giving compliments; i.e., with '我 $(I)$ ' involved in their sentences. It is interesting to note, however, that few examples of third person compliments (i.e., pronouns exhibited in the compliments are not $I$, we and you, but he, she or it; note that a combination of a pronoun and an object is also included in this category; e.g., Your article is really insightful!) exist in the English-language data collections, whereas Mandarin speakers use third person compliments (e.g., Your suggestion is really valuable!) more often than English speakers. Within this category, women rely more heavily on third person compliments than men. But further study needs to be done in order to confirm this finding, as the size of the data collection from Mandarin speakers is limited, including only 64 college students from a teachers' university in north-western China, so the sample is far from representative. 
With respect to what is being complimented, previous studies have shown that the majority of compliments focus on a few broad topics: appearance, ability, possessions, aspects of personality and performance (Holmes, 1988; Sun, 2002). Sun's (2002) Mandarin Chinese study focuses on appearance and performance. In the New Zealand English context, Holmes (1988) reports an observable tendency for women to give and receive compliments on appearance more often than men. This finding gives credence to the stereotype that women are more concerned with appearance (Herbert, 1990; Holmes, 1995). The compliments given by men to women, in particular, have an emphasis on ability or skill, with these accounting for 44 per cent of all the compliments from men (Table 1).

Table 1: Interaction between compliment topic and sex of participants

\begin{tabular}{|l|l|l|l|l|}
\hline Topic & $\mathbf{F}-\mathbf{F}$ & $\mathbf{M}-\mathbf{F}$ & $\mathbf{F}-\mathbf{M}$ & $\mathbf{M}-\mathbf{M}$ \\
\hline Appearance & $61 \%$ & $47 \%$ & $40 \%$ & $36 \%$ \\
\hline Ability/performance & $20 \%$ & $44 \%$ & $35 \%$ & $32 \%$ \\
\hline
\end{tabular}

Source: Amended from Holmes (1988).

Surprisingly, the findings of Sun's (2002) study in the Mandarin Chinese context show that both women and men compliment more frequently on performance than on appearance. This contrast between the two speech communities suggests that cultural difference is another factor to consider when researchers analyse women and men's complimenting behaviour. It must also be remembered that the participants in the Mainland Chinese studies (Sun, 2002; Duan \& Guo, 2009) were college students and there are no extant studies of compliment exchanges between people of different status in the Mandarin Chinese context. In Holmes' New Zealand data, compliments between status unequals are more likely to relate to ability/performance (54\%) rather than appearance $(27 \%)$; while, between status equals, compliments on appearance $(57 \%)$ are much more common than on ability/performance (25\%) (Holmes, 1988).

Holmes' (1988) data show that women give (67.7\%) and receive $(74.3 \%)$ more compliments than men. It is worth noticing that compliments between men are relatively rare, with these accounting for only nine per cent of all compliment exchanges. In general, complimenting behaviour occurs more frequently when women are involved. Two American studies (Wolfson, 1983; Herbert, 1990) have produced similar results, as well as the two studies carried out on Mandarin Chinese (Duan \& Guo, 2009; Sun, 2002). ${ }^{1}$

1 See the section Further Discussions and Researcher's Interpretations for further discussion of the data. 


\section{Compliment Responses}

It has been widely argued that responding to compliments appropriately is equally important in maintaining rapport or positive face of both the speaker and the addressee. In Brown and Levinson's (1987) terms, failing to do so may 'hurt the speaker's face' and hence, compliment responses can be seen as potential FTAs. Numerous studies have been done in this area, especially in the Mandarin Chinese contexts. In order to compare results from the two different speech communities more easily, I use Spencer-Oatey and Ng's (2002) three broad categories of compliment responses, with examples in both languages.

\section{Acceptance}

Appreciation; e.g., Thanks, 谢谢 (Xièxiè)

Agreement; e.g., I like it, too, 我也挺喜欢的 (Wo yě ťng xĭhuān de)

\section{Rejection/Non-acceptance}

Denial; e.g., No, I didn't do it well, 不，做得不好 (Bù, zuò de bù hăo)

Idiomatic rejection (an idiomatic phrase that is routinely used to refuse a compliment); e.g., 你过奖了 (Ň̆ guòjiăng le; lit. 'you praise me too much')

\section{Self-praise Avoidance/ Acceptance with Amendment}

Explanatory comment; e.g., A friend gave it to me, 朋友送的 (Péngyŏu sòng de) Switch of focus; e.g., Have some more since you like it, 你喜欢就多吃一点儿

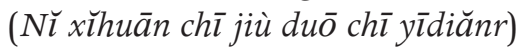

The professed ideal in English is to accept a compliment graciously (Holmes, 1995) and this belief is confirmed by the quantitative data from both the New Zealand and American corpuses (Holmes, 1988; Herbert, 1990), which show that acceptance is normally considered as the correct strategy in terms of responding to a compliment. Interestingly, Holmes (1995) found that New Zealand women and men responded to compliments in similar ways. Americans, on the other hand, appeared to accept more compliments offered by men than by women, regardless of topic and status, with compliments from women being more likely to be accepted (Herbert, 1990). 
The ANU Undergraduate Research Journal

Table 2: Acceptance responses

\begin{tabular}{|l|l|l|}
\hline & Male & Female \\
\hline By sex of complimenter & $55.3 \%$ & $20.5 \%$ \\
\hline By sex of addressee & $28.9 \%$ & $42.5 \%$ \\
\hline
\end{tabular}

Source: Reproduced from Herbert (1990).

Based on his data, Herbert (1990) suggested that the sex of the complimenter is a better indicator of the compliment response strategy used by the participants. He also pointed out that, in cross-sex interactions (i.e., $\mathrm{F}-\mathrm{M} / \mathrm{M}-\mathrm{F}$ ), women are more likely to accept compliments from men $(68.6 \%)$ rather than from women $(22.1 \%)$.

Many interesting findings have been reported in recent years by researchers in the Mainland Chinese community. Unlike the traditional belief that Mainland Chinese tend to reject compliments to show modesty (Chen, 1993), recent research by Cai (2012) on compliment response strategies used by Mainland Chinese college students shows that 'acceptance strategy' accounts for a surprising 72.3 per cent of all the compliment responses collected (from 58 males and 65 females). She attributes this change of strategy use in compliment response to the influence of what she calls 'Western cultures'. Gender distributions in her study also show a clear tendency of women accepting more compliments than men, whereas men more often choose to opt out, either by non-acceptance or non-response. These findings are consistent with Sun's (2002) study of college students, in which men choose to opt out almost twice as often as females.

\section{Further Discussions and Researchers' Interpretations}

Differences have been identified in complimenting behaviour between women and men. According to Brown and Levinson (1987), paying a compliment is a prime example of a positive politeness strategy, as it appeals to people's positive face needs; i.e., to be liked or admired by others. It follows that there exists a widespread agreement on the primary function of a compliment - to negotiate or increase solidarity (Wolfson, 1983; Holmes, 1988, 1995; Herbert, 1990). On the other hand, given that another function of a compliment is to provide positive evaluations of other people's appearance, skill or performance, a compliment can also be seen as a potential FTA, as the complimentee may disagree on the topic of the compliment that is paid (Holmes, 1995). When it comes to interpreting the universal findings that women give and receive more compliments than men in New Zealand/American English and Mandarin Chinese, there are two popular interpretations within the current literature. One is suggested by Holmes $(1988,1995)$, who claims that women are primarily 
focused on the positive effect of the speech act or expressing rapport and strengthening solidarity; whereas men tend to view compliments as judgments due to their evaluative function. In other words, women and men perceive the function of a compliment differently and, if men are more likely to regard compliments as FTAs, then it is natural that women have a higher probability of getting involved in complimenting exchanges. This interpretation matches the patterns shown in all the data. It should be noted that Duan and Guo (2009) also endorse this interpretation in their study on complimenting behaviour among Chinese college students.

Alternatively, in explaining the differences found in the language use of women and men, social roles connected to both sexes are relevant (Coates, 1993). Thus, some analysts, such as Wolfson (1983), have argued that the differences in complimenting behaviour across gender reflect social power, where women are usually regarded as being in subordinate positions in society. Due to the evaluative function of compliments, social approval is generally directed to the less powerful. According to Holmes 'praise is often directed downwards from superordinate to subordinate' (1995: 119). The tendency that is found in both languages for men to compliment women on skills and abilities can be understood as a reflection of women's subordinate status, as women are generally seen as less powerful and influential than men. Therefore, compliments in this regard are more like encouragements rather than expressions of solidarity (Herbert, 1990; Holmes, 1995). Wolfson (1983: 91) comments that 'the majority of compliments which occur in interaction between status unequals are given by the person in the higher position'. This assertion is confirmed by Wolfson's data collected from American English speakers of different social statuses. The Chinese context cannot be assessed in this category as the survey of college students does not exhibit a difference in social status.

Pomerantz's two conditions (a. agree with the speaker; and, b. avoid self-praise) are useful in analysing compliment responses and the framework has been widely used by other researchers on the same topic. According to Pomerantz (1978), complimentees are under pressure to agree with the speakers (the people who offer compliments), but on the other hand, they also want to avoid selfpraise in order to show modesty. In explaining the different strategies used in compliment response by both genders, it is also essential to note that women's language style has been claimed to be more cooperative, whereas men's is shown to be more competitive and control-oriented (Coates, 1993). Thus, the fact that women receive and accept more compliments indicates that they are more concerned with addressing the speaker's positive face and have a more cooperative attitude in conversations (Holmes, 1995). This is also consistent with Holmes' interpretation that women perceive compliments as a solidarity device. By contrast, as men are more likely to see compliments as FTAs, it follows that 
they tend to opt out in order to reduce the possibility of hurting the speaker's face. Another pattern, identified by Herbert (1990) in his American corpus in which women accepted more compliments from men than from women, seems to reinforce Wolfson's (1983) argument that women have a subordinate status in our society. Since it is generally believed that compliments usually go from higher to lower status (Herbert, 1990; Holmes, 1995; Wolfson, 1983), 'acceptance strategy' can be understood as the individual with less power trying to avoid disagreeing with a superior. In this case, the fact that women tend to accept more compliments from men in cross-sex interactions indicates the existence of status difference between women and men (Herbert, 1990).

Sun's (2002) study in the Mandarin Chinese context does not reveal the gender of the addressee as being an important factor in predicting women's compliment response strategy. His data also show that women and men use similar strategies in responding to compliments, with the majority of both women and men accepting them. Based on this, Sun (2002: 32), while acknowledging the status parity of the college students in his study, proposed that 'women enjoy more equal rights with men in modern China' than in the past. Sun supposes that different findings are probable given a more diverse sample size, as he believes social discrimination against women still exists globally and China is no exception; hence the traditional perception of women as the 'low-status' group is likely to influence people's language use and behaviour.

In her study, Holmes (1988) pointed out that the predominance of females among the data collectors is a potential source of bias (23 of her 25 data collectors were female), and this criticism is also applied to other studies done in English contexts. She commented that patterns in complimenting behaviour may be different when data collectors include equal numbers of males and females, but she believed the imbalance would not be dramatic.

\section{Implications}

Given the considerable evidence of differences in language use between women and men in their complimenting behaviour, there is the potential for miscommunication between the sexes (Coates, 1993). Studies on complimenting behaviour across gender play an important role in helping women and men better understand each other's communication styles, and hence reduce the likelihood of miscommunication. Thus, more studies on speech acts are strongly suggested and encouraged, especially in the Mandarin Chinese context, to fill the existing gaps in literature on gender-based differences in language use.

Cross-culturally speaking, studies on compliments and compliment responses can help second-language learners to understand the value system in the target 
speech community (Wolfson, 1983). By studying how people in the target speech community perform and respond to compliments, L2 (referring to a language that is not the speaker's native language) learners can acquire knowledge of manners and become more competent in the language. It follows that the findings of these studies also shed a light on foreign language teaching; communication breakdowns between cultures can be reduced significantly when the students are well informed of the practical knowledge or communicative strategies of specific speech acts in another speech community (Wolfson, 1983; Sun, 2002). Therefore, Wolfson (1983) suggests that future studies of speech acts must involve actual observations in realistic sociolinguistic contexts.

\section{Conclusion}

This paper has discussed the gender differences in complimenting behaviour in both English and Mandarin Chinese contexts. Overall, women are more actively involved in complimenting behaviour, both giving and receiving more compliments than men, especially on the topic of appearance. When it comes to choosing strategies to respond to compliments, women tend to accept compliments, whereas men tend to opt out more often than women. The findings from various researchers confirm the general observations and beliefs that women are more positive and supportive in conversations. But some analysts also suggest that the differences in complimenting behaviour reflect the power imbalance of gender in our society, with women as the subordinate group. English-language findings are mostly consistent with the few studies done by Mainland Chinese researchers. One surprising trend that has been identified in recent Mainland Chinese studies is that, contrary to popular belief, the most common strategy of compliment response by Mandarin speakers is acceptance. Due to the relatively few studies done in the Mandarin Chinese context, however, as well as the single methodology used by these researchers (Discourse Completion Test questionnaires), not enough data have been collected. As such, cultural difference as a potential factor in analysing compliments cannot be examined thoroughly. Further studies on the topic selections in compliments based on gender, as well as on differences in complimenting behaviour between status unequals, should be undertaken.

\section{Bibliography}

Brown, Penelope \& Levinson, Stephen (1987), Politeness: Some Universals in Language Usage, Cambridge University Press.

Cai, Ying (2012), 'A Study on Compliment Response Strategies by Chinese College Students', Journal of Language Teaching and Research 3(3):543-49. 
Chen, Rong (1993), 'Responding to Compliments: A Contrastive Study of Politeness Strategies Between American English and Chinese Speakers', Journal of Pragmatics 20(1):49-75.

Coates, Jennifer (1993), Women, Men and Language: A Sociolinguistic Account of Gender Differences in Language, 2nd ed., Longman Publishing: New York.

Duan, Chenggang \& Guo, Kanjun (2009), 'Hànyŭ Shūmiàn Gōngwéiyŭpiānzhōng de Xìngbié Ȳ̄nsù Yánjiū [Sex-Based Differences in Chinese Written Compliment Behavior - An Experimental Report from a Normal University in Northwestern Part of China]', Journal of University of Science and Technology Beijing, Social Sciences Edition 25(3).

Herbert, Robert K. (1990) 'Sex-Based Differences in Compliment Behavior', Language in Society 19:201-24.

Holmes, Janet. (1986b). Compliments and compliment responses in New Zealand English. Anthropological Linguistics 28,4:485-508.

- (1988), 'Paying Compliments: A Sex-Preferential Politeness Strategy', Journal of Pragmatics 12:445-65.

- (1995), Women, Men and Politeness, Longman Publishing: London.

Pomerantz, Anne (1978), 'Compliment Responses: Notes on the Co-operation of Multiple Constraints', in J. Schenkein (ed.), Studies in the Organization of Conversational Interaction, New York: Academic.

Spencer-Oatey, Helen \& Ng, Patrick (2002), 'Reconsidering Chinese Modesty: Hong Kong and Mainland Chinese Evaluative Judgements of Compliment Responses', Journal of Asian Pacific Communication, 11(2):181-201.

Sun, Zhihui (2002) 'A Study of Gender Differences in Compliments and Compliment Responses in Chinese Context', unpublished MA dissertation, School of Foreign Studies, Anhui University.

Wolfson, Nessa (1983), 'An Empirically Based Analysis of Complimenting in American English', in Nessa Wolfson \& E. Judd (eds), Sociolinguistics and Language Acquisition, Newbury House: Rowley, Mass.

Ye, Lei (1995), 'Complimenting in Mandarin Chinese', in G. Kasper (ed.), Pragmatics of Chinese as Native and Target Language. University of Hawaii. 
This text taken from The ANU Undergraduate Research Journal Volume Five 2013, published 2014 by ANU Press, The Australian National University, Canberra, Australia. 